\title{
Em tempos de mordaça, corpos dissidentes rompem o silêncio da máquina-escola
}

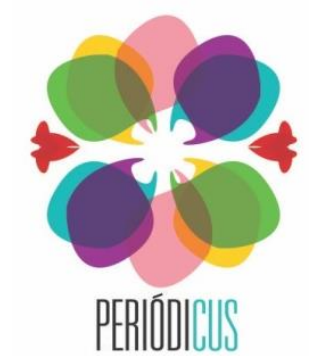

ISSN: 2358-0844 ก. II, v. 1 mai. -out. 2019 р. 271-283.

\author{
Renata Porcellis ${ }^{1}$
}

RESUMO: O artigo produz pistas sobre micropolíticas educacionais a partir de resultados de ações desenvolvidas em 2018 no Instituto Federal de Educação, Ciência e Tecnologia Sul-rio-grandense (IFSul), campus Pelotas, após a reinauguração do Núcleo de Gênero e Diversidade (Nuged). Entendendo o atual momento político de valores ultraconservadores e fascistas como um retrocesso na esfera dos direitos sociais, das lutas de corpos dissidentes, dos estudos de gêneros e sexualidades, buscou-se articular a comunidade acadêmica do campus, criando uma rede de corpos-resistência.

PALAVRAS-CHAVE: escola; revolução molecular; corpos dissidentes; singularização.

\begin{abstract}
The article creates clues about educational micropolitics from the results of actions developed in 2018 at the Instituto Federal de Educação, Ciência e Tecnologia Sul-rio-grandense - IFSul - campus Pelotas after the reinauguration of Nuged - Gender and Diversity Core. Understanding the actual political moment ultraconservatives and fascists values as a regress in the social rights sphere, of the dissident bodies struggling, of gender and sexuality studies, we seeked to articulate the campus academic community, creating a network of bodies-resistence.

Keywords: school; molecular revolution; dissident bodies; singularization.
\end{abstract}

Resumen: El artículo produce pistas sobre micropolíticas educativas a partir de los resultados de acciones desarrolladas en 2018 en el Instituto Federal de Educação, Ciência e Tecnologia Sul-rio-grandense - IFSul - câmpus Pelotas tras la reinauguración del Núcleo de Género y Diversidad - Nuged. Entendiendo el actual momento político de valores ultraconservadores y fascistas como un retroceso en la esfera de los derechos sociales, de las luchas de cuerpos disidentes, de los estudios de géneros y sexualidades, se buscó articular la comunidad académica del campus, creando una red de cuerpos-resistencia.

Palabras clave: escuela; revolución molecular; cuerpos dissidentes; singularización.

1 Técnica em Assuntos Educacionais do Instituto Federal de Educação, Ciência e Tecnologia Sul-rio-grandense Campus Pelotas, Líder do Fora da Caixa - grupo de pesquisa em educação, gêneros e sexualidades, membro da equipe diretiva do Núcleo de Gênero e Diversidade - NUGED/IFSul, Mestre em Educação e Tecnologia, Especialista em Educação, Licenciada em Artes Visuais. E-mail: renatabps@gmail.com 


\section{Linhas de entrada}

Escrevo este artigo que problematiza questões de gêneros, sexualidades, escola, a partir de micropolíticas no atual contexto do país. Em um devir-cartógrafa nego o modelo arborescente que predomina na escrita sobre sujeitos e educação, prevendo coleta de dados, método e resultados rígidos. Conforme os filósofos Gilles Deleuze e Félix Guattari (2012. p. 67).

Devir é, a partir das formas que se tem, do sujeito que se é, dos órgãos que se possui ou das funções que se preenche, extrair partículas, entre as quais instauramos relações de movimento e repouso, de velocidade e lentidão, as mais próximas daquilo que estamos em vias de devir, e através das quais devimos. É nesse sentido que o devir é o processo do desejo

Desprezo tais métodos para dar voz a uma escrita atravessada por fluxos desejantes, afecções, forças, provocações, atravessamentos, na tentativa de criação de um território intensivo, onde as forças que transitam por ele não são, nem podem ser, mensuráveis. Esse território é da ordem das intensidades, das forças. (FARINA, 2007) São essas intensidades que passam pelo território que geram experiências intensivas. O território é vivo, pulsante, fluxo onde circulam desejos, transitam intensidades que podem provocar reações, deslocamentos e, ainda que pequenos, esses deslocamentos podem alterar modos de pensar e de viver. São esses pequenos deslocamentos que abalam a molaridade da máquina-escola e nos possibilitam ensaiar revoluções moleculares, tão necessárias na atual conjuntura política. O plano molar a que me refiro, diz respeito à segmentaridade dura, extensiva, invariável, binária, visível, às macropolíticas, aos processos instituídos, às identidades família, escola, trabalho, religião -, que derivam de uma referência e funcionam por reprodução. Por outro lado, o plano molecular diz respeito às linhas flexíveis, intensivas, aos fluxos, aos desejos, aos devires, às micropolíticas, estão em um plano invisível em que não existe referência e centralização. (DELEUZE; PARNET, 1998) A organização estratificada, molar da máquina-escola, nos impulsiona a pensar em rupturas, em pequenas fissuras das linhas segmentares, dando espaço para desmoronamentos do território escolar, quiçá uma desterritorialização. Segundo Gilles Deleuze e Félix Guattari (2011), o processo de desterritorialização não depende da vontade do sujeito, ele acontece apesar do sujeito. Os movimentos de desterritorialização acontecem quando territórios perdem a força de encantamento, mundos se acabam, partículas de afeto são expatriadas, sem forma e sem rumo, não dando mais conta do mundo que existia até então. Desse movimento é necessário decorrer a reterritorialização, que nada mais é que a reconstrução de um novo território, após os 
desmoronamentos, dando sentido aos acontecimentos experienciados, aos agenciamentos, produzindo um novo mundo.

Pensando neste processo para a educação, trago alguns apontamentos sobre os estremecimentos que ocorreram em 2018 no Instituto Federal de Educação, Ciência e Tecnologia, campus Pelotas, IFSul através da reconstrução do Núcleo de gênero e diversidade (Nuged). Tal reestruturação movimentou um território duro estabelecido na escola, através dos agenciamentos com alunos e professores do campus em torno dos temas gêneros e sexualidades que gerou novas possibilidades de pensamento na educação, produção de outros mundos, outros modos de vida que se maquinaram do agenciamento desses sujeitos.

\section{Corpos estigmatizados}

Podemos pensar em corpos dissidentes como, o que chamarei de produção de subjetividade capitalística de gêneros e sexualidades, além de serem uma produção discursiva. A expressão Capitalismo Mundial Integrado (CMI), (GUATTARI; ROLNIK, 2013) faz uma crítica ao capitalismo e à globalização na contemporaneidade, em que tudo se torna efêmero e necessita ser descartado em prol de novas tecnologias e de um mercado e uma mídia cada vez mais feroz, modelando nossos corpos e modos de ser. Essa máquina se constitui de uma grande fábrica de subjetividades e nega a possibilidade de um processo de singularização. Entendendo que a subjetividade é essencialmente construída no universo social, mas não apenas em uma produção discursiva, percebemos que ela é manufaturada em escala global. A produção de subjetivação tem forma reducionista, que bloqueia processos de singularização dos sujeitos, enfraquece a molecularidade da vida e instaura processos de individuação. Segundo Félix Guattari e Suely Rolnik, as relações de disciplina e controle forjadas em sociedade obstruem os processos de singularização dos sujeitos que sucumbem à identidades serializantes:

Outro nível de individuação é o da divisão sexual: somos homens ou mulheres ou homossexuais - em todo caso, somos algo perfeitamente referenciável. Outro nível, ainda, é o da individuação nas relações socioeconômicas a classe social que somos coagidos a assumir. Todos esses exemplos nos mostram que a própria perspectiva da individuação coteja diversos processos de integração e normalização. A questão que se coloca é saber como uma micropolítica de processos singulares articula-se com esses processos de individuação.

(GUATTARI; ROLNIK, 2013, p. 46-47)

A contemporaneidade está asfixiada de práticas normativas que estabelecem e regulam como os

Periódicus, Salvador, n.11, v. 1, mai-out.2019 - Revista de estudos indisciplinares em gêneros e sexualidades Publicação periódica vinculada ao Núcleo de Pesquisa NuCuS, da Universidade Federal da Bahia - UFBA ISSN: 2358-0844 - Endereço: http://www.portalseer.ufba.br/index.php/revistaperiodicus 
sujeitos devem se portar e se vestir, o que devem sonhar, quem devem amar, como devem viver individualmente ou em grupos, sempre referenciando a um modelo a ser seguido que, invariavelmente, é de caráter transcendental, cis-hetero-normativo. Se entendermos a produção de gêneros e sexualidades como uma produção de subjetividade capitalística, podemos dizer que a inserção da criança neste "mundo" se dá antes mesmo de seu nascimento. No momento em que a ciência nos permite identificar a genitália da criança durante a gestação, ela já está capturada por uma “identidade de gênero", ou em uma visão mais ampla, em uma subjetividade capitalística de gêneros e sexualidades. Desde este momento, são fabricados modos de vida para essa criança, territórios molares a serem ocupados, quando os pais fazem escolhas, desde o nome até o que esta criança poderá, ou não, ter acesso, baseado unicamente em sua genitália. Todas as representações de feminilidades e masculinidades são fabricações da subjetividade capitalística. Os processos coletivos instituídos para a produção de subjetividade criam identidades sexuais que referenciam um modelo molar heterossexual, pois essa identidade não é uma verdade pré-discursiva, mas um efeito da subjetivação nos corpos. (PRECIADO, 2014) Um corpo organizado, nesse sentido, corresponde a um corpo cujas potencialidades estão bloqueadas por determinados dispositivos que, ao funcionarem sobre as práticas do corpo como estruturas organizacionais do agir, remetem a determinados modos de dever, vigilância e punição de si mesmo. Rechaçando a premissa de que o sujeito mulher é fundamentalmente constituído pelo biológico, Judith Butler (2015) sugere que, este mesmo sujeito, é constituído discursivamente, por tanto, esse sujeito não existe pré-discursivamente. Desta forma, aquilo que é supostamente descrito como sexo ou gênero é uma produção, uma maquinação, uma fabricação.

A crítica a esse sujeito universalizado e à identidade nos possibilita pensar o sujeito como múltiplo, complexo e contingente, rompendo a forma binária e hierárquica construída dentro de um universo molar. Existem sujeitos que rompem com a previsibilidade, subvertendo os segmentos molares dos corpos. Eles desestabilizam o campo das regularidades, não se deixam enrijecer, calcificar, cristalizar, não se deixam ser modelados, se abrem ao devir, à experimentação, aos fluxos, aos desejos enquanto produção, enquanto potência. A singularização promove um abandono da homogeneização serializante do capitalismo. Singularizar rejeita um eu universal; é inventivo, processual e contínuo.

O processo de singularização é uma das inúmeras maneiras de se viver a relação com a produção de subjetividade, e a singularização existirá sempre que houver o aproveitamento das potências que constituem a subjetividade. Tal aproveitamento se faz pelos agenciamentos. Toda vez que os fluxos se agenciam, um universo virtual se engendra e diferentes modelos e subjetivações poderão ou não se atualizar. Os agenciamentos carregam 
em si a força de produção e enunciação de sentidos heterogêneos. [...] o agenciamento é povoado de devires e de intensidades. (TEIXEIRA FILHO, 2005, p. 49)

Uma das condições de possibilidade de produção do novo é o esquecimento. Para poder produzir um grau de novidade em qualquer composição que está sendo feita, é necessário se desprender, abrir mão, esquecer de alguma maneira de fazer as coisas. É preciso abandonar o que não serve mais em um ato de repúdio e criação de um novo território. Se pensarmos no corpo bifurcado pelo gênero, parece não termos espaço para criar outros corpos. Esse corpo com vagina ou pênis, masculino ou feminino é reducionista. A sexualidade historicamente, culturalmente, socialmente funcionou a partir da identificação do órgão reprodutor com erotização, como desejo. Isso é uma produção de realidade atrelada à moralidade, no momento em que relacionamos a sexualidade à vagina e ao pênis, invisibilizamos todas as outras práticas sexuais possíveis e reforçamos um regime heterocentrado de representação de corpos. Essa significação dos órgãos e sua redução das zonas sexuais às genitálias é resultado de um disciplinamento dos corpos, das subjetividades e da própria organicidade do corpo. Atrelar significância dos órgãos reprodutivos a supostos órgãos sexuais, reduz o corpo a uma função atrelada, necessariamente, a uma moral cristã, pois apenas as práticas heterossexuais são representadas nesse pensamento, com uma finalidade reprodutiva. A questão não é negar a existência de vagina ou do pênis e suas diferenças anatômicas. O que importa é uma ressignificação desses órgãos enquanto sexuais e de toda a subjetivação capitalística que advém dessa perspectiva. $\mathrm{O}$ corpo segue sendo uma captura da cultura heterocentrada que necessita ser repensada, desierarquizada. Em outras palavras: “É preciso desterritorializar o sexo". (PRECIADO, 2014, p. 86)

$\mathrm{Na}$ escola, os sujeitos que ousam subverter a lógica molar dos corpos são marcados, estigmatizados, violentados. Conforme Teixeira Filho

\begin{abstract}
As marcas são primeiramente ritornelos e, em função de determinadas composições do campo ontológico em que são produzidas ou capturadas, elas se tornam estigmas. A palavra estigma origina-se das cinco marcas deixadas no corpo de Cristo pela Crucificação. Essas marcas teriam sido também impressas no corpo de São Francisco de Assis e outros religiosos do século XVIII. [...] a palavra estigma é anteriormente atribuída às marcas corporais infligidas pela vontade da pessoa ou de outros, e não trazidas de nascença. (TEIXEIRA, 2005, p. 35)
\end{abstract}

Corpos marcados pela diferença, não heteronormativos, são desumanizados, considerados abjetos. Essas marcas estigmatizam aqueles que fogem à normalidade. A máquina-escola tem grande responsabilidade, pois é neste território que frequentemente sujeitos dissidentes são humilhados e marginalizados e, muitas vezes, evadidos, ou melhor expulsos. É nesse contexto, em que os modos de 
produção de subjetividade universalizantes operam em favor da manutenção de identidades estanques, que o Nuged passa a travar pequenas revoluções moleculares em busca de rupturas dos padrões escolares hegemônicos, escavando espaços para a construção de novas possibilidades de escola.

\section{A força da resistência ou o desejo de uma educação menor}

A partir da reestruturação do Nuged em 2018, enfrentamos resistências fascistas desde sua reinauguração. Um núcleo que tem o compromisso com a justiça social, com o combate ao racismo, à misoginia e à LGBTfobia e com ações que visam reparar as disparidades estabelecidas por processos disciplinantes e alimentados por sentimentos de ódio. Já em nossa reinauguração, fomos atacados por discursos conservadores por proporcionar à comunidade escolar a performance de uma drag queen. $\mathrm{O}$ ataque partiu de uma mãe de aluna através do seu perfil pessoal em um rede social, onde declarava que a performance era um "espetáculo absurdo", se dizia revoltada com o despropósito da ação, questionava a proposta pedagógica e ameaçava buscar a polícia federal para uma sanção, o que realmente ocorreu. Tal publicação teve diversas respostas e compartilhamentos, tanto para validar a opinião exposta como para confrontar seu ponto de vista. Imediatamente após a grande repercussão da postagem, o grupo de professores e alunos que compõem o núcleo se reuniu para elaborar uma carta aberta à comunidade para explicar os motivos da escolha pela performance da drag queen. Para melhor entendimento, exponho um fragmento da carta:

[...] Entendemos que a arte na escola tem um objetivo para além de uma formação profissional. Ela oferece aos educandos condições de compreensão nos planos das expressões e dos significados. Através da interação com diversas formas artísticas é possível desenvolver uma reflexão crítica social de maneira mais ampla. Desta forma, entendendo que arte compreende música, arte visual, movimento, performances, encenações, dança, cinema, propomos trazer ao IFSul uma arte considerada dissidente, que possui o intuito de levantar questões e desequilibrar a ordem social vigente.

Para muito além da simples definição de homens vestidos como mulher, a arte da drag queen propõe a conscientização de uma sociedade binária e preconceituosa e induz à mudança social. Abrimos um espaço de expressão livre e valorização da arte, para lembrar que qualquer expressão artística é sempre política, e para dar visibilidade a esta arte milenar, que data desde a Grécia antiga, quando homens usavam vestidos para representar personagens femininas já que as mulheres eram proibidas de atuar. Segundo o mestre e doutorando em artes cênicas Igor Amanajás, ‘A drag queen possui uma função social cênica, seja de entretenimento ou de política que não se basta no autoprazer e no divertimento corriqueiro'.[...] Sendo assim, a performance executada pela drag queen Ravenna não apenas 
representa um momento de visibilidade a esta arte milenar e um ponto de reflexão crítica oportunizado à todos/as mas, de fato, trata-se de atividade pedagógica que vai ao encontro das diretrizes educacionais, não apenas do Brasil mas constantes em tratados internacionais de Direitos Humanos dos quais o Brasil é signatário. Como uma atividade extra classe, a nenhum/a aluno/a foi imposto a participação no evento, que ocorreu fora do horário de aula, visto que o intuito era celebrar a abertura da sala dos núcleos de ações afirmativas.

A formação da cidadania não pode se dar sem que temas de interesse público sejam tratados dentro do ambiente escolar, dentre eles destaca-se a equidade de gêneros e afetos como reflexão essencial para o reconhecimento da pluralidade e a construção do respeito à diferença [...] (NUGED, 2018, p.21)

Passado o primeiro enfrentamento com a rigidez da estrutura escolar, seguimos travando batalhas durante o resto do ano, procurando percorrer linhas de segmentaridade mais flexíveis, em busca, talvez, de linhas de fuga que desorganizassem as regularidades da escola, procurando desenhar pequenas transformações, ritmadas por velocidades caóticas, diferindo da cadência molar da máquina-escola. Enquanto formadora, escolhi problematizar verdades estabelecidas, rejeitar identidades e processos de assujeitamento, comprometer-me com uma educação ética, uma relação parresiasta com a construção de uma "educação menor".

Para Sílvio Gallo (2013), diferente de uma educação maior que trata das políticas públicas, dos parâmetros e diretrizes curriculares da ordem das macropolíticas, das políticas disciplinantes, da subjetivação, a educação menor é uma máquina de resistência, da ordem das micropolíticas, que se preocupa com agenciamentos coletivos, com o campo dos desejos, no qual o professor militante promove condições para que o saber seja produzido através de agenciamentos, ou ainda, junto a Michel Foucault (2011), o professor parresiasta, se colocando, voluntariamente, diante de uma situação de risco iminente. Em um momento político que prevê um projeto como o Escola Sem Partido, que propaga a falácia da ideologia de gênero, que elegem fascistas, falar a verdade só pode ser um ato de coragem.

O Projeto Escola Sem Partido (ESP) visa uma educação maior. Prega a falsa percepção de que a escola deve ser neutra e não considera a existência da naturalização de um conjunto de ideias e valores cis-heteronormativos-brancos, os quais foram disseminados por tanto tempo que acabaram sendo tomados como universais e tradicionais. Portanto, a propagação desses ideais deixou de ser percebido como uma doutrinação e se tornou uma transmissão de verdades absolutas. Da mesma forma, acontece com temas como gêneros e sexualidades, que desmoronam os regimes de 
subjetivação de maior rigidez. Não falamos sobre sexualidades dissidentes no ambiente escolar, como se este silenciamento fosse uma garantia da manutenção da heterossexualidade compulsória. A ruptura das linhas de segmentaridade dura precisa ocorrer, e é só através de agenciamentos que pode acontecer. Essa ruptura não deve ser entendida como um atentado contra os valores cristãos e familiares. É a partir da educação, de debates e trocas de ideias que preconceitos são desconstruídos. O ESP se preocupa com o que seria uma doutrinação ideológica através da coerção e da censura. Mas o conceito de gênero se constitui em um agente da subversão de papéis tradicionais impostos às mulheres e aos homens, no traçado de linhas de segmentaridade mais flexíveis, moleculares, proporcionando o surgimento de pequenas mudanças, provocando fluxos descontínuos, divergindo dos planos molares.

Nesse entendimento do ESP, falar sobre gêneros e sexualidades passa a ser considerado uma doutrinação. A falácia de uma ideologia de gênero nasce com setores conservadores e com a igreja como um bloqueio dos avanços na direção de equidade de gêneros e sexualidades, na perspectiva da diferença. O termo descarta toda a produção científica sobre a fabricação social de feminilidades e masculinidades, um termo inexistente no campo de estudos de gênero, consiste em uma estratégia oportunista que desloca o conceito de gênero para questões morais, buscando evitar qualquer questionamento da naturalização dos papéis cis-hetero-normativos que ordenam de forma molar uma relação entre sexo-gênero-sexualidade-desejo.

O silenciamento dessas questões, que instaura um modelo disciplinarmente normativo, machista e patriarcal, estabelece uma falta de empatia com formas legítimas de vida, de afetividade e de expressão. Amordaçar a educação priva os alunos de novas experiências, de criação de mundos, furtando-lhes um pensamento humano e a capacidade de transformar a realidade escolar e social em algo mais heterotópico. Frente a isso, entendo que o ESP não quer, de modo algum, uma escola neutra, apartidária, mas preservar a ordem molar, os valores ultraconservadores, evidenciando nitidamente sua orientação ético-política, que historicamente foi excludente, evitando a mobilidade social e negando a existência de um contingente da população não enquadrado nos padrões impostos. Tais valores conservadores e fascistas que incitam discursos de ódio, resultam em relações assimétricas de poder que desumanizam corpos dissidentes, conduzindo-os a guetos e desautorizando-lhes a existência.

A busca por uma desestabilização da escola maior através de movimentos moleculares "não seriam nada se não repassassem pelas organizações molares e não remanejassem seus segmentos, suas distribuições binárias de sexos, de classes, de partidos”. (DELEUZE; GUATTARI, 2011, p. 95) 
Frente a isso, um devir-parresiasta despertou, ainda que um franco falar ético, uma enunciação de verdades no âmbito político e social buscando intervir nos comportamentos e decisões do outro, arriscando represálias, não seja o papel que uma escola maior entende para professores, pois as verdades incômodas devem estar fora do território escolar. O exercício da verdade pode provocar estratégias de combate a microfascismos, produzir estremecimentos das identidades, corromper verdades. Tratar de assuntos delicados como preconceitos, gêneros e sexualidades levam a constantes movimentos de deslocamentos de planos estratificados. O parresiasta não é simplesmente transmissor ou reprodutor de conhecimento, ele é comprometido com uma experiência ética, com a correlação entre discurso e ação política. Assim como o professor militante que "procura viver as situações e dentro dessas situações vividas produzir a possibilidade do novo" de forma que o professor militante "seria aquele que procura viver a miséria do mundo, e procura viver a miséria de seus alunos, seja ela qual miséria for". (GALLO, 2013, p. 61)

No encontro com alunos marginalizados pela escola, percebi como esses jovens desejam uma educação flexível, porosa, que crie linhas de fuga na máquina-escola, que não os assujeitem, não os aprisionem em modelos normativos, que abra espaço para singularizações.

\section{Cartografia de uma micropolítica transviada}

Fugindo de um modelo cristalizado da escola tradicional, em um ato micropolítico, busquei a criação de máquinas teóricas e práticas que produzissem uma nova prática de desejo. Guattari nos fala que o fascismo é uma questão-chave para tratar a micropolítica do desejo no campo social

\footnotetext{
Quando falo do desejo, não estou tomando esta noção emprestada da psicanálise ortodoxa ou da teoria lacaniana. Não pretendo fundar um conceito científico; tento simplesmente, esboçar um conjunto teórico provisório, onde está em questão o funcionamento do desejo no campo social. Enquanto que não é possível manter juntos numa mesma frase o prazer e o gozo com a revolução - não se pode dizer que exista um 'prazer da revolução' ou um 'gozo da revolução' -, ninguém mais se espanta, hoje em dia, em ouvir falar de um 'desejo de revolução' ou de um 'desejo revolucionário'. (GUATTARI, 1981. p. 173)
}

Esse desejo foi fomentado nos alunos a partir de diversas abordagens: curso, eventos, criação de material teórico, rodas de conversa, campanhas e grupo de pesquisa. Associando o grupo de pesquisa que lidero, Fora da Caixa - grupo de pesquisa em educação, gêneros, sexualidades e o Núcleo de gênero e diversidade, trago a cartografia de agenciamentos de uma educação menor. Entendendo que 
Cartografar é agenciar, é documentar encontros intensivos, atravessamentos de corpos e territórios; é produção de realidades. O agenciamento é de natureza múltipla, onde agentes de natureza humana e inumana, corpórea e incorpórea são invocados. Compreendo o agenciamento como uma rede de conexões, como um rizoma, onde por exemplo, para essa cartografia, conhecimentos de diferentes naturezas são invocados para dar corpo a uma ideia [...] A cartografia pode ser entendida como um modo de registro do agenciamento, um registro desta composição de linhas que se entrecruzam, que formam uma multiplicidade. A cartografia não representa uma realidade, ela maquina, produz realidade. (SILVA, 2017, p. 101)

Criando um território aberto às interações dos sujeitos, os temas gêneros e sexualidades, ainda que atualmente silenciados nas escolas, ganharam voz, uma voz estridentes entre os alunos que se conectaram, de alguma forma, às ações de 2018. Um exemplo foi o curso "Por que falar de gênero e sexualidade na escola?" Voltado para estudantes de ensino médio com encontros semanais, abordou temas como diferença entre sexo biológico, gênero, sexualidade e expressão de gênero; transfobia, homofobia e lesbofobia; gordofobia; racismo; violência contra mulher; estereótipos de gênero e heteronormatividade. Ensinado de uma forma lúdica e fora da sala de aula, foi possível desenvolver debates e considerações sobre como transformamos certos sujeitos em abjetos e os privamos de uma vida digna. Ao pensar o lugar em que ocupamos na sociedade, reconhecemos nossos próprios privilégios e admitimos a reprodução de preconceitos estruturalmente impregnados em nossa construção. Desta forma foi possível afetar os alunos e criar um foco transformador da realidade social desses grupos.

Além do curso, outro mecanismo encontrado para romper a molaridade da escola e o silêncio da atual situação política foi a elaboração de livros com finalidade didática, voltados a adolescentes, com linguagem jovem e um visual atrativo, assim como o jogo Ser+, resultado de um projeto de ensino, que aborda temáticas sobre gêneros, sexualidades e relações étnico-raciais. Trata-se de um jogo de roleta para ser jogado em sala de aula, em sua versão de mesa, e em eventos, em sua versão gigante, no qual o educador terá em sua posse cartas divididas em: verdadeiro ou falso, perguntas e respostas e desafios podendo explorar os temas gêneros, sexualidades e relações étnico-raciais de forma prazerosa e sem tabus.

Pequenas ações tiveram um resultado bastante positivo como as rodas de conversa "Guia prático para sair do armário (se é que isso existe)" e "Basta de assédio nas IFEs", aproximando sujeitos historicamente colocados à margem na escola e sociedade como um todo, do núcleo. Tendo a oportunidade de conhecer as lutas enfrentadas no histórico do preconceito imposto à comunidade LGBTI+ e as lutas para sua inclusão social dessa comunidade, foi possível criar movimentos de 
respeito à dignidade das pessoas, assim como uma reflexão sobre bullying na escola. Em decorrência da roda sobre assédio, foi possível dar voz a alunas submetidas a assédios pelos professores que expuseram seus depoimentos em um varal da denúncia, as quais foram levadas à direção para encaminhamentos institucionais.

Tendo em vista o ano turbulento social e politicamente, alunos já atravessados pelas micropolíticas do Nuged, buscaram o núcleo para propor uma ação antifascista que culminou na campanha \#ifsulcontraaviolencia. O projeto abrangeu atividades de combate à violência em três eixos de educação: artes visuais, história e artes cênicas com o objetivo de proporcionar aos estudantes um momento de pensamento sobre violências a partir de uma proposta transversal e interdisciplinar de aprendizagem. Para a proposta artística foi utilizado o espaço dos banheiros dos alunos do campus para divulgar violências ocorridas em todo o Brasil em função de pensamentos fascistas disseminados pela campanha eleitoral através de lambe-lambes provocativos. Além disso, foi criada uma instalação que consistiu em um corredor escuro com quatro pontos focais de áudios, textos e imagens. Quatro temáticas foram exploradas: violência contra a mulher, violência contra pessoas não brancas, violência contra pessoas LGBTI+ e casos da época da ditadura. Sobre esse último tema, ainda foi realizada uma pequena exposição com pesquisas sobre pessoas desaparecidas, métodos de tortura utilizados pelo DOPS, crianças condenadas, explicação sobre milagre econômico, casos de corrupção e sobre o fascismo. $\mathrm{Na}$ área das artes cênicas, encenações foram realizadas com uma figura de autoridade censurando aulas de professores parceiros da ação, remetendo à época do regime militar, quando existiu perseguição a professores, escutas em escolas, demissões e censuras a docentes e como o atual projeto de Lei da Escola sem Partido pretende promover.

As atividades envolveram um grande número de alunos e professores com resultados extremamente positivos. A possibilidade de vivenciar experiências educacionais que divergem do modelo molar de educação transformou os sujeitos, possibilitando uma reinvenção das formas de aprender e da própria escola, e ainda, formou uma rede entre sujeitos considerados abjetos, que sentiram neste território uma possibilidade de existir e resistir.

\section{Ruminações}

O que esses corpos subversivos podem dizer e fazer sobre a molaridade da educação, sobre um território historicamente disciplinador? Temos o hábito de querer modelos, respostas fáceis e prontamente reproduzíveis. Esta não é, de forma alguma, uma proposta de revolução molecular. No 
campo da educação, precisamos provocar cada vez mais perguntas. Questionar-nos sobre esse espaço que acolhe apenas um tipo de corpo. Precisamos ampliar e, mesmo, subverter as segmentaridades rígidas da educação. Falar de sujeitos abjetos, de corpos, de gêneros, de sexualidades, e fazer reverberar novas ideias; falar da produção de desigualdades que a escola fabrica e reinventar essa realidade. $\mathrm{Na}$ atual situação política brasileira, esses sujeitos considerados desviantes, abjetos, anormais, que não se ajustam às normas da escola, fugidios de um padrão cis-hetero-normativo e de uma lógica binária, consideradas absolutas nas representações do território escolar, são aniquilados enquanto potência de existir. São macropolíticas que silenciam tais sujeitos maquinando uma suposta ideologia de gênero e defendendo a neutralidade fictícia da escola, que garante a manutenção da ideia de que, por exemplo, a homossexualidade é um desvio da heterossexualidade, que a transgeneridade é um transviamento da cisgeneridade. A heterossexualidade compulsória, assim como a heteronormatividade (MISKOLCI, 2016), tolhem a capacidade de pensamento sobre a multiplicidade dos sujeitos, a complexidade dos gêneros e das sexualidades.

Entendo o território da educação como o espaço para problematizar verdades absolutas, para negar identidades pré-estabelecidas, abrir-se à pluralidade. Não de forma a mendigar tolerância, aceitação. Mas como uma guerra, uma revolução na qual transformamos nossos corpos em resistência, nosso discurso em luta, nossos espaços em lugares de conflito, confrontando o enrijecimento da escola, os discursos enraizados, em busca de desmoronamentos que provoquem, não apenas mudanças sutis, mas desterritorializem as engrenagens enferrujadas da escola. Para isso, não basta apresentar novas ideias ou teorias utilizando procedimentos tradicionais de ensino e aprendizagem. Subverter requer reinventar, por isso, precisamos escapar à molaridade sufocante da educação, nos rebelar aos modos usuais de fazer educação. O velho educar, apresentado simplesmente em uma nova roupagem, mas utilizando das técnicas convencionais de ensino, logo é subjetivado, tornando-se molar outra vez. Para uma educação menor, é preciso continuar questionando a máquinaescola continuamente e reinventando nossas práticas.

Os estremecimentos provocados pelo Nuged movimentaram a máquina-escola e proporcionaram aos sujeitos dissidentes uma revolução molecular - ainda que provisória - contra a produção de subjetividade capitalística de gêneros e sexualidades. Pessoas negras, gordas, pessoas não binárias, homossexuais, transgêneros, descobriram que tinham voz e aprenderam a usá-la. Perceberam que o espaço que ocupam estava sendo negado a eles. Decidiram mudar essa realidade utilizando a arte, a literatura, a música, os debates como máquinas de guerra. Sabemos que os discursos de ódio têm muita força, mas as vozes dos dissidentes têm potência e não serão mais 
caladas. Ao contrário, crescerá a revolução molecular travada, pois quando um grupo mostra que possui a potência de resistir, outros sujeitos, que nunca tiveram suas vozes ouvidas, se juntam para somar e expandir a luta.

\section{Referências}

AMANAJÁS, Igor. Drag queen: um percurso histórico pela arte dos atores transformistas. Revista Belas Artes, v. 6, n.16, p. 1-24, 2014.

BUTLER, Judith P. Problemas de gênero: feminismo e subversão da identidade. 8.ed. Rio de Janeiro: Editora Civilização Brasileira, 2015.

DELEUZE, Gilles; GUATTARI, Félix. Mil Platôs: capitalismo e esquizofrenia. 2.ed. São Paulo: Editora 34, 2011. v.3.

DELEUZE, Gilles; GUATTARI, Félix. Mil Platôs: capitalismo e esquizofrenia. 2.ed. São Paulo: Editora 34, 2012. v.4.

DELEUZE, Gilles; PARNET, Claire. Diálogos. São Paulo: Editora Escuta, 1998.

FARINA, Cynthia. La Formación del Territorio: saber del abandono y creación de un mundo. In: GÓMEZ, William Moreno; QUINTERO, Sandra Maryory Pulido (org.). Educación cuerpo y ciudad. Medellín: Funámbulos Editores, 2007. p. 115-128.

FOUCAULT, Michel. A coragem da verdade: o governo de si e dos outros II: curso no Collège France (1883-1984). São Paulo: Editora WNF Martins Fontes, 2011.

GALLO, Sílvio. Deleuze \& a Educação. 3.ed. Belo Horizonte: Autêntica Editora, 2013.

GUATTARI, Félix; ROLNIK, Suely. Micropolitica: cartografias do desejo. 12.ed. Petrópolis: Vozes, 2013.

GUATTARI, Félix. Revolução Molecular: pulsações políticas do desejo. São Paulo: Brasiliense, 1981.

MISKOLCI, Richard. Teoria queer: um aprendizado pela diferença. 2. ed. Belo Horizonte: Autêntica Editora, 2016.

NUGED- Campus Pelotas. Inauguração do NAAF. 2018. Pelotas, 21 set. 2018. Facebook: NUGED - Campus Pelotas@nugedpelotas. Disponível em: https://www.facebook.com/nugedpelotas/posts/1090842307732087?_tn__=K-R. Acesso em 23 jan. 2019.

PRECIADO, Beatriz. Manifesto contrassexual. São Paulo: n-1 edições, 2014.

SILVA, Renata Barbosa Porcellis da. Mapa de intensidades: cartografia de uma transformação feminina. 2017. Dissertação (Mestrado Profissional em Educação e Tecnologia),Programa de Pós-Graduação em Educação, Instituto Federal de Educação, Ciência e Tecnologia Sulrio-grandense, Pelotas, 2017.

TEIXEIRA FILHO, Fernando Silva. Do estigma à exclusão: história de corpos (des)acreditados. São Paulo: Casa do Psicólogo: FAPESP, 2005. 